\title{
The Mind of a Good Language Learner: A Case Study of Vocabulary-learning Strategies
}

\author{
Nada Jaber Alasmari \\ King Abdul-Aziz University
}

Saudi Arabia

Received: December 1, 2019 Accepted: December 23, 2019 Published: December 24, 2019

doi:10.5296/ijele.v8i1.16116 URL: https://doi.org/10.5296/ijele.v8i1.16116

\begin{abstract}
There is a substantial amount of research in the fields of language-learning strategies and good language learners (GLLs); however, few studies have investigated vocabulary-learning strategies' use among successful learners. Thus, this paper aims to explore the vocabulary-learning strategies employed by GLLs. To fulfill this aim, a case study was conducted. The participant was a 21-year-old student who passed the standardized test of English proficiency with a high score. This study implemented three instruments, as follows: (1) a vocabulary size test to identify the vocabulary difficulty level, (2) vocabulary knowledge scale test, and (3) think-aloud protocol. In addition, the data collected were analyzed thematically. The findings showed that the participant exhibited two types of strategies. First, he used metacognitive strategies, including monitoring and planning; second, he employed cognitive strategies, which comprised retrieval, avoidance, making associations, and verification. The results indicated that there is a set of language-learning and vocabulary-learning strategies that GLLs tend to use. Moreover, these strategies incorporate but are not limited to cognitive and metacognitive skills. Given these results, this paper clarifies that the vocabulary-learning strategies a GLL displays can be used to help low-level students and learners in general further their learning.
\end{abstract}

Keywords: Good language learner, vocabulary learning strategies, metacognitive strategies, cognitive strategies 


\section{Introduction}

In the late 1970s and '80s, the field of second language (L2) acquisition witnessed a shift in the direction of research from a teacher-centered approach to one that focused on the language learner and how his/her actions effects language acquisition (Schmitt and McCarthy, 1998). Therefore, numerous studies and research have been conducted in the field of L2 acquisition to answer the question of why some language learners acquire a language better than others do.

There have been several studies done on good language learners (GLLs). For instance, Naiman (1996), Rubin (1975), and Stevick (1989) all proposed that GLLs have common characteristics and strategies they tend to use. However, most of the previous research has been interested in the strategies of language learning in general, and little research has been done regarding the vocabulary-learning strategies (VLS) used by GLLs. This gap is also noted in previous findings (Macaro, 2003; Kirmizi, 2014), which have indicated that most L2 teachers think that the topic of vocabulary needs more attention and in-depth study to help improve teaching and learning in the classroom. Therefore, one may say that learning strategies in general, and specifically, vocabulary learning strategies, have an important and recognized role in L2 acquisition, thus, studies in this area are in great demand.

This research investigates the following research question: What types of language learning strategies are implemented by GLLs, and what VLSs do GLLs favor?

To address this question, a case study on a GLL is conducted to test and recognize the strategies used and favored by the case and understand the most common VLS that GLLs tend to utilize.

\section{Literature Review}

\subsection{Learning Strategies Used by Good Language Learners}

A great amount of research in the field of GLLs has been conducted to elucidate why some learners master the language better compared with their peers. Two of the earliest researchers in this area, Rubin (1975) and Stern (1975), found that successful GLLs tend to employ several learning strategies to further their language acquisition. Thus, GLLs have a different approach to language learning compared with their peers, which includes amplifying language-learning strategies. Language-learning strategies are those strategies that affect the language directly and contribute to the improvement of the language system that the learners build while acquiring the language (Wenden \& Rubin, 1987). Furthermore, they have been defined as "the special thoughts or behaviors that individuals use to help them comprehend, learn, or retain new information" (O'Malley \& Chamat, 1990, p.1). The definition of language-learning strategies not only concerns the thoughts and behaviors employed by the learner but also extends to the operations and processes that help the learner acquire, store, and retrieve the information, which facilitates language learning and makes it more self-directed (Oxford, 2001; Griffiths, 2008).

A successful GLL tends to have certain characteristics or qualities, as identified by Rubin 
(1975) and listed in Table 1.

Table 1. Qualities of a Successful Language Learner (Rubin, 1975)

1. Is a willing and accurate guesser.

2. Has a strong drive to communicate

3. Is uninhibited and willing to make mistakes

4. Pays close attention to the form by checking patterns and analyzing them.

5. Takes advantage of all practice opportunities.

6. Manages his own language pattern's and others.

7. Pays attention to meaning.

Similarly, a study conducted by Naiman (1996) on GLL strategies suggested that GLLs tend to use five major learning techniques, as follows: (1) identifying and seeking a suitable learning environment, (2) considering language as a system rather than a monolithic entity, (3) being aware of language as a tool for communication, (4) acceptance and additivity with L2 needs and configurations, and (5) the use of monitoring and inferencing to revise L2 patterns.

Successful language learning requires the learner to be aware of the learning process and maintain active involvement in learning tasks, as well as considering the language form and communicative and functional practice; moreover, he/she must have the flexibility to shift back and forth between strategies according to diverse tasks' requirements (Ellis \& Ellis, 1994). Furthermore, GLLs often practice one of the following habits: having direct or indirect access to native speakers, watching movies, reading books or magazines, listening to radio or songs, and repeating aloud after a teacher or native speaker (Naiman, 1996; Yunus, Sulaiman, \& Embi, 2013).

Another important classification of language learning strategies is the one suggested by O'Malley and Chamot (1990),. They categorized language learning strategies into two main categories; metacognitive strategies and cognitive strategies. Metacognitive strategies concern awareness about one's own cognition and learning processes leading to choosing the most suitable strategy that serves the learning purpose (Hacker, Dunlosky, \& Graesser, 2009). In simple words, metacognitive strategies stress that the learner think about his own thinking, that the language learner is self-regulated or possesses self-control in the learning process. Such strategies include planning, monitoring, and evaluation. For instance, the planning strategy focuses on arranging and prioritizing the process of learning and breaking it down into steps, while the monitoring and evaluation strategies are concerned with the ability to control the process and the product of learning by self-checking the information, revising the information, evaluating the information and correcting the information. On the other hand, cognitive strategies concern "mental engagement with language in materials or tasks in order to develop understanding and hence learning" (Grenfell \& Harris 1999, p.44). In addition, cognitive strategies refer to interacting with the language during the attainment process and that might include language production as well (Grenfell \& Harris, 1999). In other words, cognitive strategies involve the use of mind or cognition to solve a problem or complete a 
task. Cognitive strategies include chunking, which means organizing new information and breaking it down into small parts or tasks. Retrieval, which refers to sounding out a word or repeating words to facilitate memorization. Guessing the meaning from the context. Avoidance, which means when the learner confronts ambiguity or difficult information they tend to avoid it or change it. Concept mapping, which refers to organizing the task or the information learned. Making associations, which refers to organizing the task or the information learned. Making associations, which refers to relating new information with previous knowledge the learner already poses. Lastly, verification, which refers to confirming that the product the learner produces match what he has in mind. Good language learners tend to apply certain strategies according to Naiman (1996). Yet one might say that cognitive and metacognitive strategies are essential language learning strategies that many other strategies stem from, in other terms, cognitive and metacognitive strategies could be observed in most good language learners.

\subsection{Vocabulary Learning Strategies}

To understand the lack of taxonomy of vocabulary learning strategies, one must understand that the field of language learning strategies is relatively new and developing and this applies to the area of vocabulary learning strategies as well, which results in the lack of VLS classification (Skehan, 1989). Consequently, Schmitt and McCarthy (1998) proposed a classification for vocabulary learning strategies in an attempt to address the gap in VLS. Schmitt and McCarthy adopted their VLS categorization from Oxford's (1990) classification system. They proposed four strategy groups, which are, memory, social, metacognitive and cognitive. Memory strategies are those techniques that relate the new information to previously learned information. Social strategies refer to learners' social relationships and interaction to facilitate their learning, whereas metacognitive strategies are regarded as the conscious decisions that a person undertakes to improve the learning process and the ability to plan, monitor, or evaluate the best method to learn (Bahri \& Corbima, 2015). Finally, cognitive strategies are those which refer to the act of managing the language and transforming it by the learner (Oxford 1990).

When noticing the classification proposed by Schmitt and McCarthy, the strategies in this classification are taken from larger scale language learning strategies classification, which results in some strategies appearing in both language learning strategies classifications and vocabulary learning strategies classifications, for instance, cognitive and metacognitive strategies are frequently present. As a result, the repetition of the strategy in different classifications might increase the chance of the strategy use by good language learners. Nation (2001) developed a general vocabulary learning strategies classification. The first strategy related to planning vocabulary learning. This strategy refers to identifying the goal of learning the vocabulary and specific words according to the goals they serve as well as to focus on certain aspects of the words while learning. For example, the form of the word or the meaning of the word. The second vocabulary learning strategy is source, which refers to getting information about a new word and that is done by guessing the meaning from the context, understanding and analyzing the relationship between the word's parts and checking dictionaries or asking the teacher for the meaning. The third vocabulary learning strategy is 
processes, which concerns vocabulary knowledge and ways of recalling the vocabulary and making it available to use. This includes three steps; noticing, which refers to the process of recording a word; retrieving, which refers to the connection made between a word and the retrieved knowledge; and the final step is generating, which refers to the production of the word.

\section{Methodology}

\subsection{Instruments}

1. Standardized Test of English proficiency (STEP): this test includes 100 questions to measure English language proficiency, and it is used in this study to choose a good language learner.

2. Vocabulary size test: this test is developed by Nation and Beglar (2007). The test consists of 25 items presented in multiple choice format and the test taker is required to choose the best definition of the word from four options. In this study, the test is used to identify the student with good vocabulary knowledge.

3. Vocabulary knowledge scale test (VKS): this test is is proposed by Paribakht and Wesche (1996), to measure the depth of vocabulary knowledge by asking the test taker to guess what the word means, and then produce sentences using the word. A total of 15 words are given in the test and the test taker is required to choose five of them. The words in this test are taken from the 3,000 most frequent words in the British National Corpus also known as the BNC 3000. In this study, this test alongside the 'thinking aloud protocol' is used to identify language learner strategies and vocabulary learning strategies.

4. Think-aloud protocol: is a method of observation that requires the test taker to think-aloud and verbalize all his thoughts, reflections and views while taking a test. In this study, this instrument is used alongside VKS to recognize the language learning strategies and vocabulary learning strategies implemented by the test taker.

\subsection{Procedure}

At first, this research aimed at a group of five KAU students in engineering class who have the highest scores in STEP, after comparing the scores it led to one student with the highest score referred to as $\mathrm{M}$, and he is 21 years old. After identifying the case study's participant, the participant's vocabulary knowledge was established using the vocabulary size test, which used here to determine the participant's vocabulary knowledge and thus propose level-suitable vocabulary from the BNC list. Following that, a combination of vocabulary knowledge scale test and think-aloud protocol, in which $\mathrm{M}$ was asked to verbalize his thought process while conducting the test. The data collected through think-aloud protocol were analyzed thematically.

\section{Results and Discussion}

After testing the participant and observing the process of his thoughts through think-aloud protocol, it was clear that he applies a significant amount of good language learner strategies 


\section{Macrothink $\Lambda$ Institute ${ }^{\mathrm{m}}$}

as well as vocabulary learning strategies. The following is an account of the language learning strategies applied by $\mathrm{M}$ followed up by the vocabulary learning strategies identified while testing the subject.

\subsection{Language Learning Strategies}

Some of the strategies M applied in the VKS test corresponded with the techniques used by good language learners identified by Rubin (1975) and Naiman (1996). The strategy M used frequently was focusing on the language form and paying attention to the meaning. "I chose the same word but different forms of the words". M was trying to come up with sentences using the word "hire" and he focused on conveying the meaning but using different forms. In one sentence he used "hired" in the past and in another sentence he used "hiring". As noted earlier $M$ has shown that he was able to recognize different forms of the same word and implement them in the sentences without changing the meaning of the word. Another quality of a good language learner noticed during the think-aloud protocol, is that $\mathrm{M}$ has access to native speakers. This was seen when he was asked to state what he thinks the word "valid" means. He replied: "I guess it means credible, I remember in summer school my instructor saying that your ambitions are valid no matter who you are". He relates some of the new vocabulary to previous knowledge. In this case, he heard his instructor who is an English native speaker.

\subsection{Vocabulary Learning Strategies}

During the VKS test and think-aloud protocol, several cognitive and metacognitive vocabulary learning strategies were recognized. Regarding metacognitive strategies, $M$ used the following strategies several times:

\subsubsection{Planning}

"I think of the meaning first, then how can I write it correctly then before I write the word I check the spelling". He conducted a step by step process in order to understand the word and produce accurate sentences. Furthermore, he started the test by reading all the words all together to have a general idea, and then divided the words into parts, according to the sentences he had in mind. After that, he focused on each part on its own. This is in agreement with Grenfell and Harris (1999) view of metacognitive strategies.

\subsubsection{Evaluation and Monitoring}

"The two second sentences I'm not sure about but the first sentences I think the word is correct", During the test M monitored his choice of words and the composition of the sentences. He revised the sentences he wrote and re-evaluated them and corrected the wrong structure of the sentences, He also used some evaluative strategies and checked the sentences one more time to make sure that the word is used in the correct form and conveys the correct meaning. Regarding cognitive strategies, M used the following strategies:

\subsubsection{Retrieval}

"I reread the word in my mind and I think about it", While taking the test M stopped to reread 
some words and sounded out the difficult words several times to remember the meaning or think of a correct sentence he had in mind.

\subsubsection{Avoidance}

"I feel like this word doesn't convey the exact correct meaning so I won't write it", Whenever $\mathrm{M}$ found the word he used or the sentence he composed was wrong or not accurate, he avoided writing it. Instead, he focused on the vocabulary he is confident about.

\subsubsection{Making Associations}

"I based the meaning of the word on religious background", One strategy that is useful in vocabulary learning is creating associations or relating the new word to previous knowledge. In this regard, it was noticed that $\mathrm{M}$ related some words to past knowledge or information he already had in an effort to associate the new words and familiarize them with something he already knows. This goes hand in hand with Oxford's (1990) taxonomy of cognitive memory strategy.

\subsubsection{Verification}

"I need to look at it one more time to make sure it shows the meaning", when M utilized the vocabulary in the sentences he doubled checked the sentence to make sure the words are used correctly and show the meaning accurately, also he checked the spelling of the word and the form of the sentence.

To sum up, the results of this test indicated that $\mathrm{M}$ as a good language learner relied on several language learning strategies and vocabulary learning strategies, However, two main categories were constantly present throughout the testing: cognitive strategies and metacognitive strategies (Naiman, 1996; O’Malley \& Chamot, 1990; Hacker, 2009; Oxford, 1990; Nation, 2001). Which supports the claim mentioned in the literature review, that those two strategies are essential learning strategies that other strategies stem from.

\section{Conclusion}

To conclude, this study aimed to identify the types of learning strategies and vocabulary learning strategies amplified by good language learners. Furthermore, this paper investigates this issue through an empirical case study of a good language learner's language learning strategies. Interestingly, the results shown in this study imply that a GLL appears to have a parallel pattern of language learning strategies and vocabulary learning strategies that mainly but not exclusively include cognitive and metacognitive strategies. Those strategies were present in the testing and identified in the discussion section. Understanding these strategies and recognizing the types of strategies frequently used by GLL, might give an insight about the effective strategies that low-achievers and overall learners could make use of in order to excel in learning the language. Moreover, identifying and augmenting these strategies might help improve teaching and learning in the field of vocabulary acquisition.

\section{Implications and Reconditions}

One implication of this paper might be the difficulty to generalize the data on a broader level 
due to the nature of this research paradigm. In order to make the results more generalizable, quantitative data is needed to capsulate a larger sample. In addition, this study identifies some vocabulary learning strategies used by GLL, Thus, it is recommended that teachers incorporate these strategies in vocabulary activities and content planning, to help struggling students to learn new word items easily. Moreover, further research on the effect of the cognitive versus metacognitive strategy for the successful acquisition of new vocabulary is recommended.

\section{References}

Bahri, A., \& Corebima, A. D. (2015). The Contribution of Learning Motivation and Metacognitive Skill on Cognitive Learning Outcome of Students within Different Learning Strategies. Journal of Baltic Science Education, 14(4). Retrieved from http://journals.indexcopernicus.com/abstract.php?icid=1169904

Beglar, D., \& Nation, P. (2007). A vocabulary size test. The language teacher, 31(7), 9-13.

Ellis, R., \& Ellis, R. R. (1994). The study of second language acquisition. Retrieved from https://escholarship.org/uc/item/6wg540t3

Grenfell, M., \& Harris, V. (1999). Modern languages and learning strategies: In theory and practice. London: Routledge.

Griffiths, C. (2008). Lessons from good language learners. https://doi.org/10.4324/97802038764281

Hacker, D. J., Dunlosky, J., \& Graesser, A. C. (2009). Handbook of metacognition in education. https://doi.org/10.4324/9780203876428

Kirmizı, O. (2014). Measuring vocabulary learning strategy use of Turkish EFL learners in relation to academic success and vocabulary size. World Journal of Education, 4(6), 16. https://doi.org/10.5430/wje.v4n6p16

Macaro, E. (2003). Teaching and learning a second language: A guide to recent research and its applications (1 ed.). London: Continuum

Naiman, N. (1996). The good language learner (Vol. 4). Toronto: Multilingual Matters.

Nation, I. S. (2001). Learning vocabulary in another language. https://doi.org/10.1017/cbo9781139524759

O'malley, J. M., O'Malley, M. J., \& Chamot, A. U. (1990). Learning strategies in second language acquisition. https://doi.org/10.1017/CBO9781139524490

Oxford, R. (1990). Language Learning Strategies: What Every Teacher Should Know. Newburg House/Harper \& Row, New York. Now Boston: Heinle \& Heinle.

Oxford, R. (2001). Language Learning Strategies. In D. Nunan \& R. Carter (Eds.), The Cambridge guide to teaching English to speakers of other languages (1 ed., pp. 166-172): Cambridge University Press. 
Rubin, J. (1975). What the" good language learner" can teach us. TESOL quarterly, 9, 41-51.

Schmitt, N., \& McCarthy, M. (1997). Vocabulary: Description, acquisition and pedagogy (1 ed.). Cambridge: Cambridge University Press.

Stern, H. H. (1975). What can we learn from the good language learner? Canadian Modern language review, 31(4), 304-319.

Stevick, E. W. (1989). Success with foreign languages: Seven who achieved it and what worked for them. New York: Prentice Hall.

Wenden, A., \& Rubin, J. (1987). Learner strategies in language learning. New Jersey: Prentice/Hall International.

Wesche, M., \& Paribakht, T. S. (1996). Assessing second language vocabulary knowledge: Depth versus breadth. Canadian Modern language review, 53(1), 13-40.

Yunus, M. M., Sulaiman, N. A., \& Embi, M. A. (2013). Malaysian gifted students' use of English language learning strategies. English Language Teaching, 6(4), 97. https://doi.org/10.5539/elt.v6n4p97

\section{Appendix}

Appendix 1. Vocabulary Size Test

1. Choose the suitable definition for each word:

1. see: They <saw it>.

a closed it tightly

$\mathrm{b}$ waited for it

c looked at it

d started it up

2. time: They have a lot of <time>.

a money

$b$ food

$\mathrm{c}$ hours

$\mathrm{d}$ friends

3. period: It was a difficult <period>. a question

$\mathrm{b}$ time

$c$ thing to do

d book

4. figure: Is this the right <figure>?

a answer

$b$ place

c time d number

5. poor: We <are poor>.

a have no money

b feel happy

$\mathrm{c}$ are very interested

$\mathrm{d}$ do not like to work hard

6. microphone: Please use the <microphone>.

a machine for making food hot

$\mathrm{b}$ machine that makes sounds louder

c machine that makes things look bigger

$\mathrm{d}$ small telephone that can be carried around

7. nil: His mark for that question was $<$ nil $>$.

a very bad

b nothing

c very good

$\mathrm{d}$ in the middle

8. pub: They went to the $\langle p u b\rangle$. 
a place where people drink and talk

$b$ place that looks after money

c large building with many shops

$\mathrm{d}$ building for swimming

9. circle: Make a <circle>.

a rough picture

b space with nothing in it

c round shape

d large hole

10. dig: Our dog often <digs>.

a solves problems with things

$\mathrm{b}$ creates a hole in the ground

$\mathrm{c}$ wants to sleep

$\mathrm{d}$ enters the water

11. pro: He's <a pro〉.

a someone who is employed to find out important secrets

b a stupid person

c someone who writes for a newspaper

$\mathrm{d}$ someone who is paid for playing sport

12. compound: They made a new <compound>.

a agreement

$b$ thing made of two or more parts

$c$ group of people forming a business

$\mathrm{d}$ guess based on past experience

13. deficit: The company <had a large deficit>.

a spent a lot more money than it earned

$\mathrm{b}$ went down a lot in value

$\mathrm{c}$ had a plan for its spending that used a lot

of money

$\mathrm{d}$ had a lot of money stored in the bank

14. strap: He broke the <strap>.

a promise

b top cover

c shallow dish for food

$\mathrm{d}$ strip of strong material

15. weep: He <wept>.

a finished his course

b cried

c died

d worried
16. haunt: The house is <haunted $>$.

a full of decorations

$b$ rented

c empty

d full of ghosts

17. cube: I need one more <cube>.

a sharp thing used for joining things

b solid square block

c tall cup with no saucer

d piece of stiff paper folded in half

18. butler: They have a <butler $>$.

a man servant

b machine for cutting up trees

c private teacher

$\mathrm{d}$ cool dark room under the house

19. nun: We saw a <nun>.

a long thin creature that lives in the earth

$\mathrm{b}$ terrible accident

c woman following a strict religious life

$\mathrm{d}$ unexplained bright light in the sky

20. olive: We bought <olives>.

a oily fruit

b scented flowers

c men's swimming clothes

$\mathrm{d}$ tools for digging

21. shudder: The boy <shuddered>.

a spoke with a low voice

b almost fell

c shook

d called out loudly

22. demography: This book is about <demography>.

a the study of patterns of land use

$b$ the study of the use of pictures to show

facts about numbers

$\mathrm{c}$ the study of the movement of water

$\mathrm{d}$ the study of population

23. malign: His <malign> influence is still

felt.

a good

b evil

c very important

d secret 
24. strangle: He <strangled her>.

a killed her by pressing her throat

$b$ gave her all the things she wanted

c took her away by force

$\mathrm{d}$ admired her greatly

25. dinosaur: The children were

pretending to be <dinosaurs>.

a robbers who work at sea

b very small creatures with human form but with wings

c large creatures with wings that breathe fire $d$ animals that lived an extremely long time ago 
Appendix 2. Vocabulary Knowledge Test (VKS)

1. Choose 5 words and answer the questions in the table below :

Hesitate
Hire
Echo
Abbey
Abandon
Cope
Soil
Valid
Platform
Pulse
Magnitude
Way
Belief
Youth
Zone




\begin{tabular}{|l|l|l|l|l|}
\hline word & $\begin{array}{l}\text { What do you think the } \\
\text { word mean? }\end{array}$ & $\begin{array}{l}\text { What does the } \\
\text { word mean? }\end{array}$ & $\begin{array}{l}\text { Make a phrase } \\
\text { using this word }\end{array}$ & $\begin{array}{l}\text { Make two } \\
\text { sentences } \\
\text { using this } \\
\text { word }\end{array}$ \\
\hline & & & & \\
\hline & & & & \\
& & & &
\end{tabular}

\section{Copyright Disclaimer}

Copyright for this article is retained by the author(s), with first publication rights granted to the journal.

This is an open-access article distributed under the terms and conditions of the Creative Commons Attribution license (http://creativecommons.org/licenses/by/3.0/). 